Provided for non-commercial research and education use. Not for reproduction, distribution or commercial use.

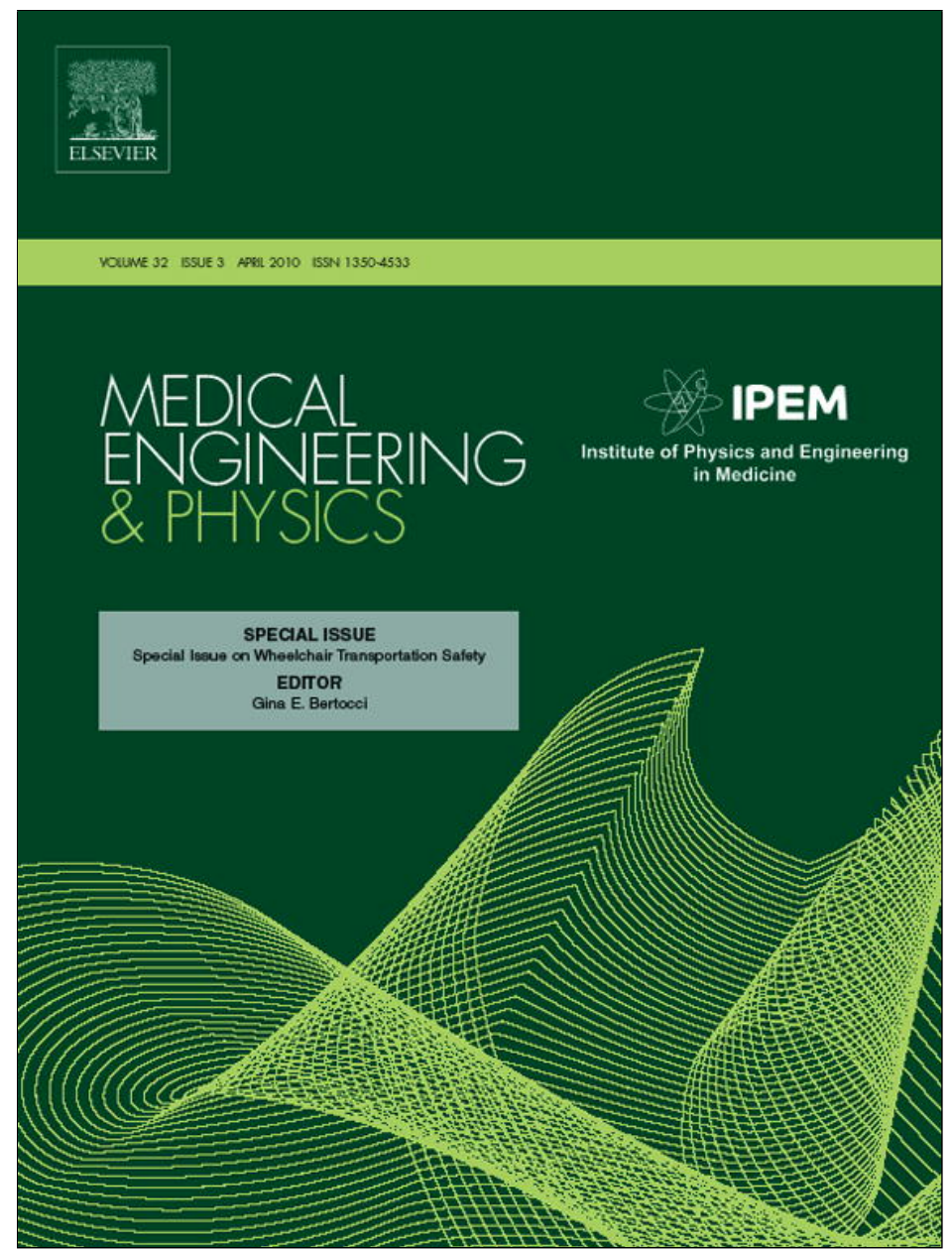

This article appeared in a journal published by Elsevier. The attached copy is furnished to the author for internal non-commercial research and education use, including for instruction at the authors institution and sharing with colleagues.

Other uses, including reproduction and distribution, or selling or licensing copies, or posting to personal, institutional or third party websites are prohibited.

In most cases authors are permitted to post their version of the article (e.g. in Word or Tex form) to their personal website or institutional repository. Authors requiring further information regarding Elsevier's archiving and manuscript policies are encouraged to visit:

http://www.elsevier.com/copyright 


\title{
Reducing non-collision injuries in special transportation services by enhanced safety culture
}

\author{
Anders Wretstrand ${ }^{\mathrm{a}, *}$, Jan Petzäll ${ }^{\mathrm{b}}$, Per-Olof Bylund ${ }^{\mathrm{c}}$, Torbjörn Falkmer ${ }^{\mathrm{d}}$ \\ a Department of Technology and Society, Lund University, Lund, Sweden \\ b Swedish Transport Agency, Norrköping, Sweden \\ ' Emergency and Disaster Medical Center, University Hospital, Umeå, Sweden \\ ${ }^{\mathrm{d}}$ Curtin University of Technology, Perth, Australia; Jönköping University, Sweden; Linköping University, Sweden
}

\section{A R T I C L E I N F O}

\section{Article history:}

Received 15 July 2008

Received in revised form 30 June 2009

Accepted 4 September 2009

\section{Keywords:}

Wheelchair

Transportation

Safety

Organization

Procedure

Culture

Focus groups

\begin{abstract}
A B S T R A C T
Previous research has pointed out that non-collision injuries occur among wheelchair users in Special Transportation Services (STS - a demand-responsive transport mode). The organization of such modes is also quite complex, involving both stakeholders and key personnel at different levels. Our objective was therefore to qualitatively explore the state of safety, as perceived and discussed within a workplace context. Focus groups were held with drivers of both taxi companies and bus companies.

The results indicated that passengers run the risk of being injured without being involved in a vehicle collision. The pertinent organizational and corporate culture did not prioritize safety. The drivers identified some relatively clear-cut safety threats, primarily before and after a ride, at vehicle standstill. The driver's work place seemed to be surrounded with a reactive instead of proactive structure.

We conclude that not only vehicle and wheelchair technical safety must be considered in STS, but also system safety. Instead of viewing drivers' error as a cause, it should be seen as a symptom of systems failure. Human error is connected to aspects of tools, tasks, and operating environment. Enhanced understanding and influence of these connections within STS and accessible public transport systems will promote safety for wheelchair users.
\end{abstract}

(C) 2009 IPEM. Published by Elsevier Ltd. All rights reserved.

\section{Introduction}

\subsection{Special transportation services}

In Sweden, Special Transportation Services (STS - a demandresponsive transit system like paratransit, dial-a-ride, etc.) are provided to $\sim 5 \%$ of the population. Between 10 and $20 \%$ of these travelers are wheelchair users and most passengers use manual wheelchairs [1]. The usual solution is the door-to-door, demand-responsive taxi trip. Local and regional regulations qualify the traveler for the service, and the fare is partially subsidized ( $\sim 80 \%)$. Traveler bookings are usually via computer-aided traffic planning systems, which handle customer registration, eligibility restrictions, geographic information, routing, timetabling, vehicle scheduling and dispatching. As the planning system, while focusing on efficiency, optimizes the use of the available vehicle fleet, the desired trip times might be changed, which of course could affect perceived travel quality. Thus, the travelers must adapt to time changes, be prepared for alternate routes, and share the ride with

\footnotetext{
* Corresponding author at: Department of Technology and Society, Lund University, P.O. Box 118, SE-221 00 Lund, Sweden. Tel.: +46 46 2229125; fax: +46 46123272

E-mail address: anders.wretstrand@tft.lth.se (A. Wretstrand).
}

other, perhaps unknown, travelers [2]. The STS organization is often quite complex, involving drivers, booking staff, traffic planners, software programmers, people at the responsible transit authority and finally policy makers and politicians responsible for funding and level of service. The outcome of the organizational efforts, the performed and perceived service quality has also gained increased attention, since passengers seem to run the risk of being injured without being involved in a vehicle collision [3].

Few, if any, studies have examined the organization of STS in Sweden from a critical user's perspective. The studies so far have only targeted particular travel quality outcomes. Therefore, this research project sought to analyze safety, using a mixed methods approach, involving both quantitative as well as qualitative research methods. Non-collision incidences and injury costs were presented in Bylund et al. [3]. As part of that project outcome, this paper will discuss safety in a public transit and STS perspective, focusing on wheelchair users. It presents findings from parts of the qualitative studies within the project.

\subsection{Safe organizations}

\subsubsection{General issues}

In Sweden, vehicle safety regulations comply with existing EU directives. The national regulations describe ramp/lift design and 
the requirement of tested wheelchair tie-down solutions. Occupant restraints must be used (the passenger is ultimately responsible). Moreover, so-called $\mathrm{M}_{1}$ vehicles ( $\leq 8$ passengers) must have threepoint belts. Additional safety requirements may be added in local procurement documents, but these mainly address procedures. Lately, local requirements have restricted wheelchair size according to the ISO standard and also forbidden scooters as seats in vehicles.

In order to approach safety issues other than the obvious technical aspects (WTORS) and the frailty of the passengers [4-7], it is important to address the fact that STS systems involve people with different employers, working together in order to create functioning services. From an occupational perspective, it has been suggested that organizational variables influence environmental variables as well as group process variables, which, in turn, influence individual precursors to behavior [8]. There is also support for commitment-based safety practices that influence the perceived safety climate [9]. Safety frameworks have been suggested, e.g. conceptualizing safe behavior as consisting of four stages or phases: hazard appraisal, decision making, initiation, and adherence [10]. Such theoretical reasoning could be of great benefit in the analysis of the diversity of the staff and the resulting traffic safety outcome for wheelchair-seated passengers.

The drivers are at the core of the STS services. Therefore, fleet safety focusing on both property damage and injury prevention emerges as a major occupational health and safety issue. However, it has been shown that transport organizations do not address fleet safety properly or have an ad hoc approach, being more reactive than proactive [11].

\subsubsection{Creating safe organizations}

How do organizations go about creating safe environments and procedures? Rochlin observed that "... .maintenance of a high degree of operational safety depends on more than a set of observable rules or procedures... While much of what the operators do can be formally described one step at a time, a great deal of how they operate... is 'holistic"' (p. 1557) [12]. In other words, operational safety is more than the management or avoidance of risk or error. So defined, it seems to be an ongoing inter-subjective construct, not readily measured. Safety is represented by the interaction between operating personnel and managers. Maintaining safe operations so defined is partly a communicative act. Therefore, it also could be distorted by well-meant but improper interventions aimed at eliminating human error.

Apart from this holistic labeling of safe organizations, it is likely that at least parts of poor safety in STS could be attributed to key personnel committing simple errors. Dekker [13] pointed at a fundamental double bind, wherein people may:

- fail to adapt procedures when adaptation proves necessary,

- attempt procedural adaptations that may fail.

In safety research and human factors today, at least two different views of human error and human contribution to accidents can be found. One view sees human error as a cause of failure. There, human error is the cause of most accidents, and the engineered systems are safely built. The threat to safety therefore comes from unreliable behavior. Thus, the primary focus of safety promotion should be clear procedures, automation, training, and discipline. The other view sees human error not as a cause, but as a symptom, of systems failure. Safety is not inherent in systems - due to contradictions between different goals - and therefore, people have to create safety [14].

\subsubsection{Aspects of the public transport work force}

The development today in many organizations is towards a limited core of workers, employed on long-term contracts, together with a number of provisional, contractual and temporary workers. Temporary work allows employers to handle their workforce more flexibly [15]. The transit industry, however, will face some challenges here, and Clarke has argued that it will be more difficult to integrate employees with diverse working arrangements, compared to a workforce of permanent employees, into a corporate safety culture [16].

The environmental ergonomic aspects must also be monitored. According to Machin and De Souza, there has not been sufficient emphasis placed on the physical health and well-being of drivers. Perceptions of management's commitment to health and safety may turn out to be predictors of the amount of drivers' emotional well-being as well as drivers' unsafe behavior. Therefore, industry should approach driver health and safety in an integrative way, incorporating prevention of hazardous situations, developing and communicating a positive safety culture [17].

\subsection{Objective and scope}

The overall objective of the current study was to qualitatively explore the state of safety as perceived and discussed by drivers. The driver group was selected on the following assumption. The operating part of the STS organization was considered the cornerstone, turning travel quality policy into practice, with driver performance thus the final output.

Since passengers also seem to run the risk of being injured without being involved in a vehicle collision, a more specific aim of the study was to elicit possible causes for incidents and occurring wheelchair user injuries, as discussed among drivers themselves. The emergent themes were to be situated within a workplace context.

The study participants were Swedish STS drivers working either in taxis or specially designed minivans. The drivers were employed by taxi or public transit (PT) operators, which in turn were contracted by municipalities or transit authorities to perform STS services on a long-term basis (3-5 years).

\section{Methods}

\subsection{General issues}

In order to gain access to the everyday safety talk, group interviews or discussions are appropriate tools for creating a situation resembling chats and discussions held in everyday life, particularly in public participatory transit planning activities [18]. What particularly characterizes the group interviews is their use of group interaction and their ability to highlight respondents' attitudes, priorities and perspectives [19,20]. Different perspectives are accessible, since the researchers then operate within a social network [21]. These were the main reasons for selecting the focus group approach.

\subsection{Participants}

Five consecutive focus groups (see Table 1) were arranged in cities in southern Sweden. Participants were recruited through the STS agency, which contacted the contracted transport companies. The focus groups were held at formal meeting places, without participation of either agency staff or company management. The exact number of focus groups was not determined at the outset. After working with the five groups, however, the emerging themes and categories were finally considered theoretically saturated. These criteria are further described in the analyses section below. 
Table 1

Five consecutive focus groups in cities in southern Sweden.

\begin{tabular}{|c|c|c|c|c|c|c|}
\hline Group no. & City & Recruited sample & No. of participants & No. of different companies & Moderators, interviewers & STS drivers' union ${ }^{\mathrm{a}}$ \\
\hline 1 & Lund & 12 & 5 & 2 & 1 & $(\mathrm{t})$ \\
\hline 2 & Malmö & 10 & 4 & 1 & 1 & $(\mathrm{t})$ \\
\hline 3 & Helsingborg & 6 & 6 & 3 & 2 & $(\mathrm{t})$ \\
\hline 4 & Karlskrona & 6 & 4 & 2 & 1 & (b) \\
\hline 5 & Gothenburg & 6 & 6 & 2 & 2 & (b) \\
\hline Total & & 40 & 25 & 10 & b & \\
\hline
\end{tabular}

a (t) taxi; (b) bus. This refers to the drivers' collective agreement with the employer, regulation working hours, salary and other legislative occupational issues.

$\mathrm{b}$ In total, three researchers were actively involved.

The main differences among the groups were the type of drivers' collective employment agreements. Drivers working under "taxi conditions" usually had regular taxi services experience, whereas drivers working under "bus transit conditions" had a background as bus drivers. Other differences between "taxi" and "bus" were the type of vehicle in operation. Generally, taxi vehicles are of type $\mathrm{M}_{1}$ (sedan cars, EU labeling) with fully flexible operation, while the larger minivans and minibuses $\left(\mathrm{M}_{2}\right.$ and $\left.\mathrm{M}_{3}\right)$ operated by the "bus drivers" usually are dispatched to fixed assignments and recurrent schedules if required (e.g. school transports for children with special needs or non-emergency hospital transports). However, all vehicles operated in the local demand-responsive STS system.

\subsection{Focus group items}

The sessions lasted for $2 \mathrm{~h}$ each. The questioning path served as a catalyst for the safety discussion, and was conducted through a Power-Point slide sequence. The key questions followed a sequence that separated the travel chain in five steps: arriving at the vehicle; boarding the vehicle; during the ride; alighting the vehicle; and departing from the vehicle (Table 2).

\subsection{Analyses}

All focus group sessions were tape recorded, and notes taken about significant comments were collected and summarized. The analysis procedure could be described as content analysis, a basic approach where previous group sessions and theoretical framework served as input into the subsequent top-down analysis [22]. For practical reasons, the results section in the current paper is a very condensed presentation of the rich, thick oral descriptions.

The data were schematized according to the three main issues in the questioning path and categorized according to emerging thematic concepts. The following subheadings were used: STS general issues (vocational assessments, traffic economy, customers' benefits, safety and travel quality); transport to and from the vehicle, boarding and alighting; during the ride; injury and non-injury events - frequency and cause (temptation to neglect mandatory or recommended procedures and handling, in case of injury or noninjury events, suggestions for improvements or solutions).

\section{Results}

\subsection{STS - general issues}

\subsubsection{Vocational assessments}

A common subject that emerged in several groups was that STS provides services of paramount social importance. Frequently, the drivers saw evidence of passengers' appreciation of the service as such. Pride in the drivers' own work was expressed both implicitly and explicitly. Certain character skills were regarded as compulsory in order to meet systems' and passengers' requirements. Of equal importance was the ability to drive and manage urban traf- fic, handle the accessibility and safety equipment, and listen and adapt carefully to individual needs. Some drivers saw themselves as the real experts in the STS organization, whereas others who initiate and plan system changes know very little of "the real world out there".

\subsubsection{Traffic economy}

The issue was raised whether STS services could mean profitable business for taxi or bus operators. The answers showed awareness of market competition. For some, the competition was regarded as being increasingly tighter. Others were employed in firms relatively new in the operating business - indicating a still functioning transport market with space for new entrepreneurs. Differences arose among attitudes between the "taxi" and "bus" groups. The taxi drivers pointed towards the possibility of earning extra money by putting more effort into their work, e.g. actively seeking new assignments. Some of them felt that the bus drivers complained too often, and didn't take initiatives of their own. Some of the bus drivers, on the other hand, described the taxi operators in terms of poor working conditions, exploitation of the drivers, and high numbers of low-wage immigrants resulting in skewed competition.

What characterizes STS is that the travel demand reaches its morning peak during normal off-peak hours, and an extended peak early in the afternoon. Friday and Saturday nights are rush hours for regular taxi services, and during these nights the travel demand is quite low, which also allows for more conventional working hours. Among those working regularly and with fixed salary (no performance bonus), this was seen as a good system. Others, while having a more flexible salary they could influence, pointed to incentives as an advantage. From another perspective, the fixed price contracts could seem quite illogical. The computer-aided planning and dispatch system optimizes the stream of bookings into vehicle routes (marginal mileage cost equals zero). This can lead to a large number of longer links without passengers, regarded as poor efficiency by both passengers and drivers.

Drivers used to other forms of operating contracts mentioned strange optimizing effects. The dispatch algorithms prioritize vehicles with low unit prices, influencing drivers in competing high-price companies, who still work under incentive agreements. This is a fact that the drivers themselves cannot influence, causing frustration over systems effects.

\subsubsection{Customer benefits}

As mentioned earlier, the drivers feel that the passengers are satisfied with the services. It was discussed why younger passengers would be more critical to the services and the level of quality. Students, in particular, were considered especially demanding. Existence of a Swedish Handicap Ombudsman, general change of attitude towards disabled people, and the accessibility discourse could trigger younger disabled activists to repeatedly claim their legal rights. Older wheelchair users often have age-related disabilities and poorer health, which could more easily be regarded as normal. 
The social dimension was a recurrent part of working as a driver. It gives the occupation more meaning than just transportation. In the collegial group, the importance of STS was often boosted and ascribed as a social lifeline for the passengers. However, the need for protection and distance between passengers and driver was necessary. Some passengers were hard to please and often caused trouble. Others were said to show an immense need for conversation and for someone to listen to their large or small worries. It was seen as somewhat challenging to always keep up appearances and show interest.

\subsubsection{Safety and travel quality}

Shifting the discussion theme from general issues towards quality and safety usually induced disinterest. Safety initially seemed as a non-issue. Some utterances mirrored a common defeatist standpoint: suddenly accidents just happen, and it's hard to take evasive action. Other observations were connected to the drivers' skills and experiences as key to safe trips. The interpretation of the disinterest was: (a) the previous issues of organization were perceived as far more important; (b) the vehicles nowadays are always equipped with WTORS (four wheelchair-mounted straps, a three-point belt and a separate posture-belt if the wheelchair lacks such). However, as will be seen below, some important safety aspects were revealed.

\subsection{Transport to and from the vehicle}

Weather, road and pavement management, and the design of parking lots were examples of items supporting or obstructing the passenger transport to or from the vehicle. In some cases it was unclear whether passengers actually had the physical capacity to move themselves. Drivers of vans or minivans usually claimed higher assessment competence. The taxi drivers argued that precise information regarding the particular customer frequently was missing or false.

The issue of wheelchair stair-climbing devices was common among drivers working in urban areas with buildings or blocks of flats without elevators. Although saving effort and sometimes inevitable, the safety while using these powered devices assisting the drivers while negotiating steps and stairs was sometimes questioned. According to drivers some passengers expressed doubts or even fear, particularly heavy passengers with large wheelchairs descending steep stairs.

Helping passengers disembark while other passengers remained seated could cause worries. Should the door be locked or not (e.g. preventing passengers with dementia from escaping) in case of internal fire or another external threat? Other problems arising were absence of reception: no one was present to meet a passenger, whether friends, relatives or staff.

No typical event emerged to direct questions, but eventually the discussion circled around lifting wheelchairs, stair-climbing devices, and drivers forgetting to deploy the anti-tippers. Two drivers described injuries sustained because of forgotten antitippers. Furthermore, lightweight wheelchairs in combination with heavy occupants were seen as a safety threat. One driver told a story of a wheelchair actually collapsing in the street after negotiating a curb.

... it's strange that accidents don't happen more often, though - and when they do, well, as odd events, like beyond what's ordinary...

\subsection{Boarding and alighting}

The boarding discussions could be separated into two groups. Drivers of taxis mentioned inaccessible vehicles, although passengers nevertheless approved of these vehicles. Even wheelchair users thought that taxis were preferable, although wheelchairs had to be disassembled and the passengers lifted into the front passenger seat. Drivers complained particularly about this lifting procedure, not because of handling people but because it was such a strenuous act and a precursor of acute back pain.

In case of a minivan, van, etc., the themes were low-floor (accessibility, reliability and ride comfort), usable entrance steps, foldable ramps or electrically operated lifts. The discussion of the benefit of low-floor vehicles showed that passengers also liked the design. The boarding and alighting discussions often ended up in wheelchair maneuverability and various types of wheelchairs. Two important properties of a wheelchair were highlighted: weight and steering (maneuverability of powered wheelchairs). Problems were identified in driving up or down a ramp and maneuvering inside the vehicle. Powered wheelchairs are often controlled with a joystick, individually adapted to each user (logic, sensitivity, etc.). It was a bit unclear whether it was the responsibility of the (powered) wheelchair user or the drivers to assure safe boarding and alighting.

...those passengers suffering from dementia, who steer with a joystick, they're unable either to maneuver or stop - they simply just cross the ramp edge...

\subsection{During the ride}

The large city focus groups stressed both traffic situation and poor pavement quality and maintenance as causing severe discomfort to both drivers and passengers. Some complaints were made regarding certain vehicle types, prone to poor comfort. A particular incident type was highlighted: turning right and passing an elevated bicycle lane bump, evoking discomfort and risk since vehicles with high centers of gravity tend to sway.

Gradually the conversations revealed that the recent years of safety discussion has had effect on technology. The manual wheelchairs have been improved with suitable anchor points for the straps. The vehicles all had three-point seat belts even for wheelchair passengers. At the same time, some of the drivers still seemed not to know how to properly use the safety equipment. Also, quite an important observation, some drivers pointed out that passengers occasionally claimed that their postural support belt provided sufficient protection and refused to use the three-point belt. The discussion in several groups shifted over to a tutorial from some drivers sharing their knowledge of the WTORS.

Despite the promising reasoning about safety improvements, stories were told about those odd, but maybe crucial moments, where drivers end up in dire straits. Some drivers also dared to avoid group consensus, by emphatic statements of a failing safety practice.

...if you attach the wheelchair with [four-point] straps, it won't move, but yet, accidents have occurred, so anyway there is something conspicuous about it...

\subsection{Injury and non-injury events}

Table 3 presents a summary of causes of direct and potential passenger injuries. The table shows that not only common aspects of wheelchair transportation safety are important, but also almost every design and systems element in the travel chain influences safety. However, initially most groups agreed that injuries seem to be rare. That passengers still could be injured was attributed to external factors and stress.

\subsubsection{Temptation to take short cuts}

The participants were goaded by the moderator to admit negligence. Some participants seemed relieved to admit their own 
Table 2

The questioning path guiding the drivers' focus groups.

\begin{tabular}{|c|c|c|c|}
\hline Q\# & Content & Q\# & Content \\
\hline 0 & $\begin{array}{l}\text { Safety and STS (overview): } \\
\text { Passenger safety } \\
\text { Design and technology } \\
\text { Handling, system } \\
\text { Human factors }\end{array}$ & 5 & $\begin{array}{l}\text { Boarding and placing procedure: } \\
\text { What is important for safety? } \\
\text { What can happen? } \\
\text { Why? }\end{array}$ \\
\hline 1 & $\begin{array}{l}\text { Who benefits from STS? } \\
\text { The passengers? } \\
\text { The drivers and operator managers? } \\
\text { The PTAs and municipalities? } \\
\text { The society? }\end{array}$ & 6 & $\begin{array}{l}\text { During the ride: } \\
\text { What is important for safety? } \\
\text { What can happen? } \\
\text { Why? }\end{array}$ \\
\hline 2 & $\begin{array}{l}\text { Travel standard factors: } \\
\text { Cost } \\
\text { Safety } \\
\text { Comfort } \\
\text { How important is safety? }\end{array}$ & 7 & $\begin{array}{l}\text { Deploying, alighting: } \\
\text { What is important for safety? } \\
\text { What can happen? } \\
\text { Why? }\end{array}$ \\
\hline 3 & $\begin{array}{l}\text { Transport to the vehicle: } \\
\text { What is important for safety? } \\
\text { What can happen? } \\
\text { Why? }\end{array}$ & 8 & $\begin{array}{l}\text { Transport to the destination: } \\
\text { What is important for safety? } \\
\text { What can happen? } \\
\text { Why? }\end{array}$ \\
\hline 4 & $\begin{array}{l}\text { Boarding/entering the vehicle: } \\
\text { What is important for safety? } \\
\text { What can happen? } \\
\text { Why? }\end{array}$ & 9 & $\begin{array}{l}\text { Injuries? } \\
\text { Procedures/degree of reporting? } \\
\text { Do accidents happen at all? }\end{array}$ \\
\hline
\end{tabular}

shortcomings or erroneous decisions. Their own post-hoc analyses of what went wrong contained an element of self-blame.

...yet these tipping accidents [during the ride], they also occur during off-peak hours, so you just can't blame the traffic, can you. . .

\subsubsection{Reporting events}

Some groups admitted under-reporting of incidents. The drivers seemed well-informed of the legal situation and what was required. All drivers worked under conditions involving some kind of control and reporting system. Still, reasons for non-reporting were mentioned: assessment of significance, risk of salary cuts, risk of being fired or even sued, passengers reluctant to report incidents, etc.

...some of the passengers don't dare to complain, and if I ask them if all went ok and they say yes, it doesn't seem to be necessary to start something big, you know they would like to ride with us again next week...

\subsubsection{Safety problems and solutions}

Creativity seemed lacking while pursuing enhanced safety. One common reflection was that some drivers were considered to be careless or unlucky fellows, whereas others were simply inexperienced or temporary workers. These drivers seemed to affect the reputation of other (good) drivers. If these could be identified and transferred to other assignments, it would be perceived as an improvement. Other suggestions dealt with technology: better emergency equipment, automatic or semiautomatic WTORS, WTORS deploy detectors, compartment airbags, and unified wheelchair requirements for use as seats in vehicles. Finally, organizational matters were stressed: a clear-cut legal framework for responsibility between passengers, drivers, and other staff members, extensive training for new drivers, and field practice for administrative staff.

... some passengers refuse to use seat belts, and we haven't enough time to argue, and if you also lack management support, you simply resist such arguments ...therefore we need better guidelines that we can stick to... and recognition in the offices...

\section{Discussion}

The focus group results highlighted several important issues. Below, a few of these will be discussed:

- STS is an important and appreciated mode of transport with engaged drivers. Does the system also support drivers' safe behavior?

- A trip is a sequence - a travel chain with five steps. Which of these should be prioritized to enhance passenger safety from a driver's perspective?

- The study supports previous findings indicating that STS passengers run the risk of being injured without being involved in a vehicle collision. Could a focus on safety culture within the organization minimize hazards?

- Adoption of a cultural perspective - proposing a simplified framework for improving and monitoring safe behavior and organizational procedures.

\subsection{Supportive system properties}

Frequently, the drivers expressed pride in their own work. It is quite likely that the sample consisted of highly motivated individuals, keen to discuss work-related issues. The discussions might have been less vivid and fruitful if the sample had been random. Nevertheless, the social dimension was seen as a motivating factor, giving additional value to the profession of providing mobility for wheelchair users.

However, since the drivers were the interface between service providers and customers, this and other inspiring vocational factors could easily be neutralized by systemic flaws. All system errors will sooner or later be conveyed both ways through the interface. Therefore, it is of utmost importance that all key system personnel should understand:

- the consequences of procedure deviations,

- the importance of the critical paths of the travel procedure: booking, confirmation, dispatch, time buffers, departure, transport, arrival, and feedback. 


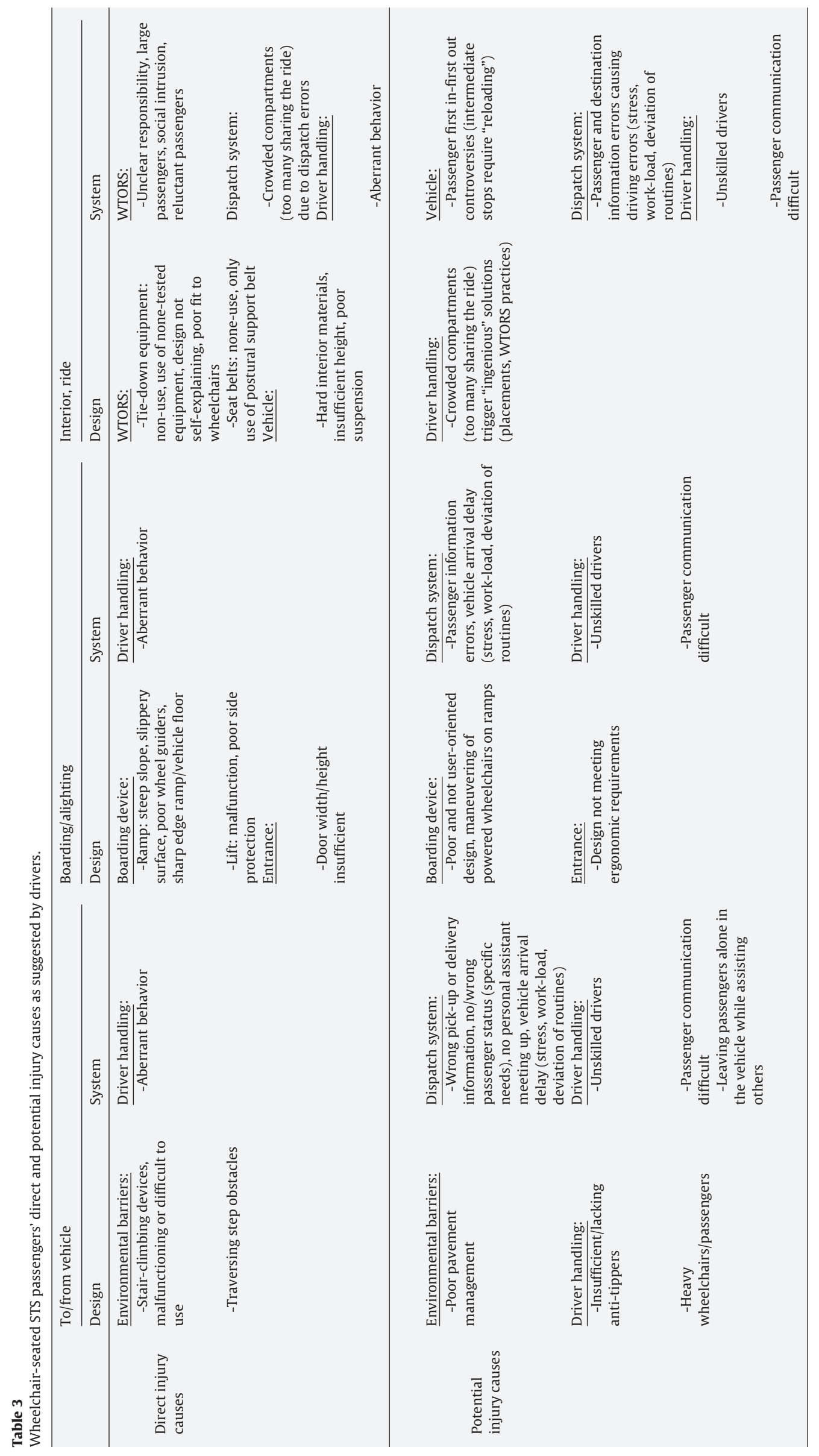


Table 4

Safety issues, travel chain: suggested target areas for safety improvements.

\begin{tabular}{|c|c|c|c|c|}
\hline \multirow[t]{2}{*}{ Travel chain parts } & \multicolumn{4}{|l|}{ Target areas } \\
\hline & Driver & Vehicle & System & Passenger \\
\hline \multirow{4}{*}{ To/from vehicle } & Driver training: & & $\begin{array}{l}\text { Specific passenger requirements } \\
\text { included in dispatch orders }\end{array}$ & Passenger training: \\
\hline & -Service encounter & & $\begin{array}{l}\text { Real-time delay reporting system } \\
\text { (mobile phones, PDAs) }\end{array}$ & $\begin{array}{l}\text {-Wheelchair step-rider } \\
\text { use together with driver }\end{array}$ \\
\hline & $\begin{array}{l}\text {-Disability awareness and } \\
\text { knowledge }\end{array}$ & & $\begin{array}{l}\text { Distinct pick-up and leave } \\
\text { information for drivers AND } \\
\text { passengers }\end{array}$ & \\
\hline & $\begin{array}{l}\text {-Stair-climbing devices handling } \\
\text {-Techniques for traversing step } \\
\text { obstacles }\end{array}$ & & & \\
\hline \multirow{3}{*}{ Boarding/alighting } & Driver training: & Low-floor vehicle & $\begin{array}{l}\text { Specific passenger requirements } \\
\text { included in dispatch orders }\end{array}$ & Passenger training: \\
\hline & -Ergonomics & $\begin{array}{l}\text { Ramp/lift design and } \\
\text { maintenance }\end{array}$ & Eligibility data must specify: & $\begin{array}{l}\text {-Use of ramps (powered } \\
\text { wheelchairs) }\end{array}$ \\
\hline & -Ramp/lift handling & & $\begin{array}{l}\text {-Whether driver or passenger } \\
\text { maneuvers } \\
\text {-Role of assisting person }\end{array}$ & $\begin{array}{l}\text {-Compartment } \\
\text { maneuvering }\end{array}$ \\
\hline \multirow{3}{*}{ During the ride } & Driver training: & WTORS & $\begin{array}{l}\text { Specific passenger requirements } \\
\text { included in dispatch orders }\end{array}$ & $\begin{array}{l}\text { Choice of wheelchairs must } \\
\text { consider }\end{array}$ \\
\hline & $\begin{array}{l}\text {-Anchoring and disengaging of } \\
\text { WTORS }\end{array}$ & -User friendly, flexible fit & Real-time online-system: & The use as seats in vehicles \\
\hline & $\begin{array}{l}\text {-Reduction of accel./deceleration } \\
\text { levels }\end{array}$ & $\begin{array}{l}\text {-WHC anchor points } \\
\text { mandatory } \\
\text { Implementation of ISA } \\
\text { (intelligent speed adaptation) }\end{array}$ & $\begin{array}{l}\text {-GPS, route } \\
\text { guidance/track-keeping } \\
\text {-Incident/deviation reports }\end{array}$ & \\
\hline Aim & $\begin{array}{l}\text { Performance: } \\
\text {-Awareness and skill } \\
\text {-Reduced work load }\end{array}$ & $\begin{array}{l}\text { Design: } \\
\text {-Safety } \\
\text {-Usability and efficiency }\end{array}$ & $\begin{array}{l}\text { Support: } \\
\text {-Materializing safety culture } \\
\text {-Adjusting conditions to user } \\
\text { needs }\end{array}$ & $\begin{array}{l}\text { Travel quality: } \\
\text {-Safety } \\
\text {-Comfort and mobility }\end{array}$ \\
\hline
\end{tabular}

The drivers' working experiences with older and disabled passengers varied, underscoring the problem of provisional and contract workers, which must be acknowledged by managers. The discussions also revealed that safety was almost a non-issue, at least initially. It was obvious that the drivers' discussions often tended to shift towards other STS issues perceived as more important to the occupation. This might indicate inadequate systems support. Therefore, a supportive system needs to address the driver situation as a whole, since the total workload might have grave negative influence on individual behavior, responsibility and level of performed safety activity [8].

\subsection{Priority in the travel chain}

It was quite difficult to separate the transport to/from the vehicle from the boarding/alighting procedure. In both cases, the centrality was the interaction between passenger and driver, whereas the ride sequence was associated with vehicle and technology. This human interaction [23] could be affected by both passengers' and drivers' conditions, the built environment, the weather, wheelchair and vehicle design, and various booking prerequisites. Since the factors affecting this interaction were highly dynamic and often system dependent, one interpretation of the results was that the sequences before and after the actual ride should be prioritized. This is supported by the findings in Bylund et al. [3].

Moving through buildings or doors, traversing obstacles (such as curbs) and negotiating ramps and various slopes are more or less difficult for wheelchair users. In fact, these situations are the very reasons for not using regular public transit and for requiring assistance in various ways. Besides professional knowledge and experience, sufficient time to perform these assisting services is essential. This could only be achieved by a STS system that takes into account the possibility of a deviation from the normal, being able to give a little extra time for leaving the apartment, boarding or anchoring/deploying safety equipment to a custom built wheelchair.

Table 4 suggests some general safety improvements in all parts of the travel chain. An enhanced safety culture will incorporate all key personnel in the effort to prevent injury. The table shows that although WTORS play an important role, focus on other parts of the travel chain will provide enhanced safety. However, since STS services impose high societal costs, it is imperative that the safety measurements also support an efficient transport system. Hence, an increased use of real-time online systems may support fleet optimization, while at the same time such a system would decrease passengers' perceived waiting time.

\subsection{An injury-preventing safety culture}

Non-collision injuries happen throughout the travel chain, obviously indicating a gap between policy and practice. Thus the question: could a focus on safety culture eliminate or at least minimize the hazards?

Passenger injuries were attributed to external factors and stress. Although injuries were considered quite rare from a driver's individual perspective, several stories were recalled. These could show a pattern, ranging from an extreme situation to an odd moment with no particular features. Other causes were unlucky fellows or inexperienced and temporary workers. The latter fact must be given increased focus, since the deregulation of the taxi and demandresponsive transit industry continues to create increased market competition. Increased demand for low-wage personnel, temporary workers $[15,16]$ or drivers from other countries with poor 

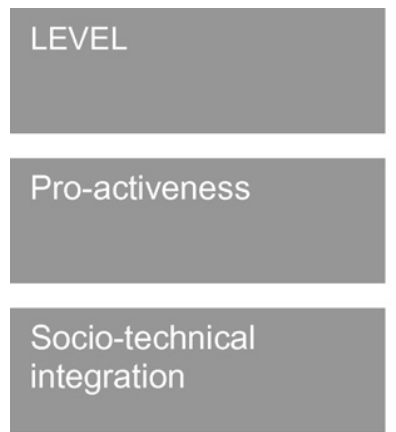

Value-consciousness
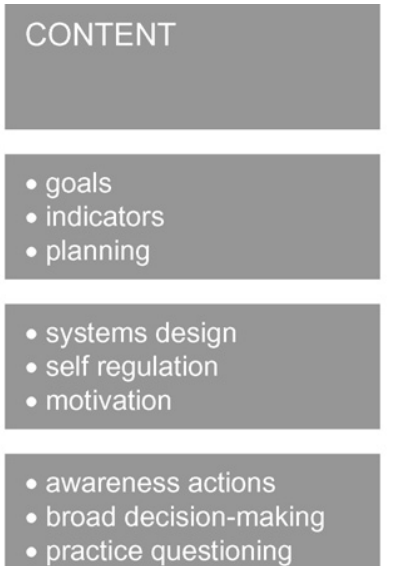
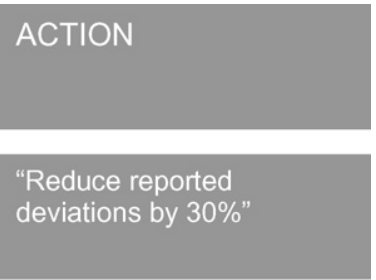

"Linked and clear-cut

driver and booking centre personnel incentives"

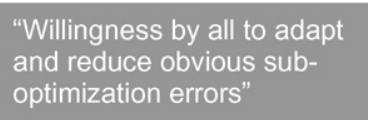

Fig. 1. Safety culture framework, adapted from Grote and Grote \& Küntzel $[25,26]$.

language skills are all obstacles to creating a unified safety culture. The STS vehicles were also operated by taxi companies that either solely, partly or only occasionally perform these services. Thus, the necessary experience with disabled passengers' special needs varies substantially.

Does the organization help the driver to deliver safe services? After all, the driver is the core of the service. This could lead to a system with under-reporting of deviations, incidents or even injuries, since drivers have very little to gain by filing a report if it is not obviously necessary. DeJoy et al. [24] found that organizational climate made a significant contribution to safety climate. This suggests that improved overall climate, where all key personnel are aware of each other's contribution to realizing STS aims, could easily improve safety. The fact that reasons for non-reporting of incidents and injuries were brought up for discussion pointed at further need for a more open climate within the whole organization.

\subsection{Solutions}

Where, then, do we find the solutions or starting points for a superior safety culture? Is the solution to create rigid procedures? Or is it to start with developing a sound safety culture, where everything should be reported, in order to share experiences and constantly improve the routines in the learning team?

According to Dekker [13], procedures and control lead towards passivity. If we instead proceed on the assumption that drivers never go to work with the intention of harming anyone, the system and its parts must be fully supportive in each aspect of the tasks to be performed. However, common WTORS systems were good examples of the existing STS technology: not self-explanatory, wide open for "innovative use", thus not user-friendly or supportive. The fact that the postural support belt could be used as replacement for the three-point belt indicated both a lack of knowledge and poor training; improvement here could provide drivers with appropriate arguments for convincing reluctant passengers. Technology implementations must therefore be seen from a user perspective in order to be integral parts of a smooth STS system.

The fact that the industry is notably characterized by temporary workers from different backgrounds must be considered. This could be an obstacle when implementing safe procedures and a safety culture. However, Clarke suggests that developed human resource management techniques and practices could be ways of developing and maintaining positive safety attitudes across all types of employees [16].

\subsection{Safety culture framework}

The concept culture has been used frequently so far. The reason will be made obvious below. Grote argued that culture could be seen as a means to provide sufficient coordination and integration of otherwise unlinked key personnel in the system [25] (such as drivers and booking personnel). The idea is that culture will create a set of assumptions and decision premises that preserve coordination and centralization parallel to decentralized decision making. Thus, safe behavior and compliance will occur without surveillance, standardized procedures or strong hierarchies.

Grote and Künzler [26] proposed a socio-technical model of safety culture, which has been simplified as a framework for the purposes in the current study; see Fig. 1. Acting on three different levels are three concepts: pro-activeness (e.g. strategic and operational safety goals encompassing all key personnel in the transportation service); socio-technical integration (e.g. highly-motivated operators who can control the output); valueconsciousness (e.g. acknowledging drivers' questioning attitude regarding planning practices). Fig. 1 could constitute an injurypreventing safety culture, as it encompasses the whole travel chain and all key personnel.

By applying this theoretical framework, the desired outcome a reduced number of injured passengers - could be approached in a top-down sequence incorporating goals, system factors and values and norms. We suggest that the workplace conditions are just as important factors for passenger safety as are the design and implementation of vehicle and safety technology, given the fact that a majority of the vehicle-related injuries are non-collision events [3].

\section{Conclusion}

Wretstrand et al. [2] have described wheelchair user incidents and injuries in STS, as commonly occurring during the ride (braking/accelerating) and during boarding/alighting. Lately, research by Wretstrand et al. [27] suggests that incidents during vehicle standstill are even more common. In order to reduce these incidents, existing safety procedures must be reconsidered in order to promote safe behavior and develop a learning organization. The study revealed problems with lifts, ramps, steps and stair-climbing devices. It pointed at physical exertion while assisting the frail passenger and the increased risk of erroneous handling. These are facts known and discussed before [28]. However, in order to create safe services, a more holistic perspective must be adopted. It is difficult 
to design a procedure to eliminate errors ("the human factor"), without negative side-effects. Therefore, it could in fact be argued that only human factors will eventually lead to better safety culture. Understanding this will improve safety and allow for sound evaluation of the technology in use [13].

The study used drivers' oral acknowledgment in trying to understand why hazards exist. It is likely that at least parts of poor safety in STS could be attributed to simple errors (by booking center staff, drivers, passengers, etc.). People could fail to adapt procedures when adapting proves necessary, or attempt procedural adaptations that may fail. However, adopting the view that drivers are the interface of the service and its various inherent qualities, the performed output will strongly depend upon the ability of the organization to support the drivers' different tasks.

A sound approach will create a supportive environment, reducing the drivers' workload and eventually developing an enhanced safety culture within the whole STS organization. According to Dekker [13], organizations therefore need to:

- Monitor the gap between procedure and practice.

- Try to understand why the gap exists.

- Help people to develop skills to judge when and how to adapt.

- Resist simply telling people to comply and follow procedures in order to promote safety and safe behavior.

Promoting STS and public transit safety could be accomplished by creating a supportive, transparent environment that acts effectively on the pro-active level, the socio-technical integration level, and the value-consciousness level.

\section{Acknowledgements}

This study was founded by the Swedish Road Administration (Grant No. AL90 B 2003:26842). The authors would also like to thank the participating drivers and their companies for valuable discussions.

\section{Conflict of interest}

None.

\section{References}

[1] SIKA. Special transport services and national special transport services 2004 Stockholm: The Swedish Institute for Transport and Communications Analysis: 2005. p. 6.

[2] Wretstrand A, Petzäll J, Ståhl A. Safety as perceived by wheelchair-seated passengers in special transportation services. Accident Analysis and Prevention 2004;36(1):3-11.

[3] Bylund P-O, Wretstrand A, Falkmer T, Lövgren A, Petzäll J. Injuries in STS travel-a multi-methodology approach to estimate incidence and societal costs. Traffic Injury Prevention 2007;8:180-8.
[4] Bertocci G, Manary M, Ha D. Wheelchairs used as motor vehicle seats: seat loading in frontal impact sled testing. Medical Engineering and Physics 2001;23(10):679-85.

[5] Cooper RA, Boninger ML, Spaeth DM, Ding D, Guo S, Koontz AM, et al. Engineering better wheelchairs to enhance community participation. IEEE Transactions on Neural Systems and Rehabilitation Engineering 2006;14(4):438-55.

[6] Hobson DA. Wheelchair transit: an unresolved challenge in a maturing technology. Journal of Rehabilitation Research \& Development 1997;34(2) [VII-2].

[7] Shaw G. Wheelchair rider risk in motor vehicles: a technical note. Journal of Rehabilitation Research and Development 2000;37(1):89-100.

[8] Cheyne A, Oliver A, Tomas JM, Cox S. The architecture of employee attitudes to safety in the manufacturing sector. Personnel Review 2002;31(5-6):64970.

[9] Barling J, Hutchinson I. Commitment vs, control-based safety practices, safety reputation, and perceived safety climate. Canadian Journal of Administrative Sciences-Revue Canadienne Des Sciences De L Administration 2000;17(1):76-84.

[10] DeJoy DM. Theoretical models of health behavior and workplace self-protective behavior. Journal of Safety Research 1996;27(2):61-72.

[11] Anderson W, Plowman B. In: Safety I.C.o.W.A.C.o.R., editor. An integrated approach to fleet safety in the workplace. Perth: Insurance Commission of Western Australia; 1999. p. 205-13.

[12] Rochlin G. Safe operation as a social construct. Ergonomics 1999;42(11):1549-60.

[13] Dekker SWA. Failure to adapt or adaptations that fail: contrasting models on procedures and safety. Applied Ergonomics 2003;34(3):233-8.

[14] Dekker SWA. Reconstructing human contributions to accidents: the new view on error and performance. Journal of Safety Research 2002;33(3):371-85.

[15] Felfe J, Schmook R, Six B, Wieland R. Contingent employees' commitment to agency and client organization: antecedents and consequences. Zeitschrift Personalpsychologie 2005;4(3):101-15.

[16] Clarke S. The contemporary workforce-implications for organisational safety culture. Personnel Review 2003;32(1-2):40-57.

[17] Machin MA, De Souza JMD. Predicting health outcomes and safety behaviour in taxi drivers. Transportation Research Part F: Traffic Psychology and Behaviour 2004;7(4-5):257-70.

[18] Gaber J, Gaber S. Using focus and nominal group techniques for a better understanding of the transit disadvantaged needs. Transportation Planning and Technology 2002;25(2):103-20.

[19] Krueger RA, Casey MA. Focus groups: a practical guide for applied research. Thousand Oaks, CA: Sage; 2000.

[20] Morgan DL. Focus groups as qualitative research. Thousand Oaks, CA: Sage; 1997.

[21] Barbour RS, Kitzinger J. Introduction: the challenge and promise of focus groups. In: Barbour RS, Kitzinger J, editors. Developing focus group research: politics, theory and practice. London: Sage; 1999. p. 1-20.

[22] Wilkinson S. Focus groups. In: Smith JA, editor. Qualitative psychology. London: Sage; 2003.

[23] Sulek JM, Lind MR. Fail-Safe methods for paratransit services. Journal of Public Transportation 2005;8(4):65-85.

[24] DeJoy DM, Schaffer BS, Wilson MG, Vandenberg RJ, Butts MM. Creating safer workplaces: assessing the determinants and role of safety climate. Journal of Safety Research 2004;35(1):81-90.

[25] Grote G. Understanding and assessing safety culture through the lens of organizational management of uncertainty. Safety Science 2007;45(6):63752.

[26] Grote G, Künzler C. Diagnosis of safety culture in safety management audits. Safety Science 2000;34(1-3):131-50.

[27] Wretstrand A, Bylund P-O, Petzäll J, Falkmer T. Injuries in special transport services -Situations and risk levels involving wheelchair users. Med Eng Phys 2010;32:248-53.

[28] Petzäll J. Traversing step obstacles with manual wheelchairs. Applied Ergonomics 1996;27(5):327-42. 